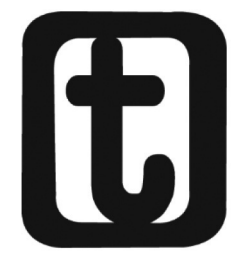

\title{
SERVIÇO SOCIAL E RELAÇÕES RACIAIS: caminhos para uma sociedade sem classes
}

\author{
SOCIAL WORK AND RACE RELATIONS: paths for a classless society
}

\author{
Sheila Almeida Dias ${ }^{1}$
}

\section{RESUMO}

Pensando na lacuna existente entre o Serviço Social e a temática étnico-racial, o presente estudo se desenvolve com o objetivo de responder não apenas a inquietudes pessoais, mas, também, contribuir para aproximar a categoria dos assistentes sociais de um debate com indiscutível importância, uma vez que estes trabalham com as múltiplas expressões da questão social, com a elaboração e execução das políticas públicas e sociais resultantes da mobilização e organização da sociedade civil na luta por direitos, livre de opressões e sobretudo, sem classes. O presente artigo é parte do meu projeto de mestrado apresentado à comissão examinadora do Programa de Pósgraduação em Serviço Social da Universidade Federal do Rio de Janeiro em 2013. Como se trata de uma pesquisa inicial, a metodologia por ora utilizada consiste apenas em uma revisão bibliográfica, com leitura crítica das obras citadas ao longo da problematização e outras referentes a temas como política pública, social, cidadania, democracia, questão étnico-racial, entre outras.

PALAVRAS-CHAVE: Serviço Social; Étnico-racial; Classes.

\section{ABSTRACT}

This article is part of my object of study in the master's and was presented as a project to the examination board of the graduate program in social service

1 Assistente Social, formada pela Escola de Serviço Social da Universidade Federal do Rio de Janeiro ESS/UFRJ. Atualmente é bolsista CAPES e está cursando mestrado em Serviço Social pelo programa de Pós-Graduação em Serviço Social da UFRJ (PPGSS/ESS/UFRJ). Tem experiência em Serviço Şocial com ênfase nas áreas de Políticas Sociais, relações raciais e de gênero. 


\section{tempordlis}

of the federal university of Rio de Janeiro in 2013. Thinking about the gap between the Social Service and the ethnic-racial theme this study, is developed in order to respond not only personal concerns, but also help to raise the category of social workers in a debate with unquestionable importance, since they work with multiple expressions of the question social, development and implementation of public and social policies resulting from the mobilization and organization of civil society in the struggle for rights, free from oppression and, above all, without classes. As this is an initial research, the methodology used for now consists only of a literature review and critical reading of the works cited throughout the questioning and other pertaining to issues such as public policy, social, citizenship, democracy, ethnic-racial issue.

KEYWORDS: Social Work; Ethnic racial; Class.

Submetido $-25 / 03 / 2014$

Aceito - 25/05/2015

Para a amiga e irmã Franciane Cristina Menezes

(In memorian).

Navegar é preciso, e aqui ficamos a navegar ainda que sem você... Por você, pelos outros e por nós! Contra o racismo e todas as formas de opressão, navegamos.

\section{INTRODUÇÃO}

Entendemos que para o enfrentamento ao racismo, e às variadas formas de opressões, como as de classe, gênero, geracionais, etnia, sexualidade, raça e outras, é preciso haver um compromisso político concreto, articulado entre Estado, sociedade civil, e, sobretudo, com ampla participação dos movimentos sociais. Sabemos que o que resulta de tais opressões são marcas profundas, alimentadas pelo sentimento de inferioridade e subjugação do indivíduo, que contribuem para a solidificação das contradições existentes e necessárias aos interesses econômicos do capitalismo.

Realizaremos uma breve contextualização histórica sobre a construção das relações raciais, culturais, sociais e econômicas no Brasil. Neste artigo, buscamos interpretar como foi possível tal construção se efetivar, embora fossem marcadamente contraditórias. É importante entender como as opressões de classe e étnico-racial, 
(eixo principal da nossa discussão) contribui para a manutenção da ordem capitalista vigente, e o que as tornam determinantes na guerra de posições entre as classes.

Objetivamos com este trabalho, contribuir para a efetivação do respeito às diversidades existentes, das culturas múltiplas, visto que estas se somam à continuidade da luta pela afirmação de direitos e emancipação humana ${ }^{2}$, que garantam aos indivíduos o lugar de protagonistas e partícipes dos projetos políticos, sociais culturais e econômicos neste país.

A naturalização das diferenças e desigualdades raciais são fatores que se combinam e são intrínsecos um ao outro, contribuem para a fragmentação da identidade do negro (a), e não permitem que o indivíduo perceba a lógica perversa existente nas expressões das desigualdades e diferenças a que são submetidos cotidianamente, sobretudo, por consequência da sua pertença étnico-racial. O que resulta de tal lógica é a ausência de alternativas, no desenvolvimento de uma reação coletiva, contrárias à posição de inferioridade que lhes são atribuídas constantemente.

Considerando que as relações sociais estão marcadas por assimetrias, podemos afirmar que o fator raça/cor é determinante para a exclusão ou inclusão dos indivíduos. Neste sentido, a exclusão da população negra é constatada em todos os indicadores sociais³, demonstrando que tal população permanece em situação de profunda desigualdade, situando-se nos segmentos mais pauperizados da sociedade brasileira. Embora reconheçamos que existam avanços na legitimidade política das ações de enfrentamento ao racismo e de promoção da igualdade entre negros e brancos, verifica-se, também, a existência de barreiras ideológicas e políticas de predominância dessa

2 Utilizo-me do conceito de emancipação no sentido atribuído por Marx, descrito nos Manuscritos econômico-filosóficos: "A superação da propriedade privada é, por conseguinte, a emancipação completa de todas as propriedades e sentidos humanos; mas ela é esta emancipação exatamente pelo fato de estes sentidos humanos e propriedades terem se formado humanos, tanto subjetiva quanto objetivamente" (1983, p. 174). Portanto, segundo Marx, a emancipação parcial é possível nos marcos do capitalismo, a emancipação universal só é realizável através da completa superação do capital. Cf. Marx (1970, pp. 114-115)

3 Ver indicadores como Ipea e Dieese (2008/2009). Ainda IBGE, microdados PME. Tabulação LAESER (Banco de Dados publicado no periódico Tempo em Curso Faculdade de Economia/UFRJ) (2009). 


\section{tempordlis}

abordagem no meio acadêmico, estatal e societário. Sobre isto, afirmamos que estas assimetrias se solidificaram de tal forma, com largas estruturas fincadas sob o pilar da falsa democracia racial.

Conforme apontado no enunciado o presente artigo é parte do meu projeto de pesquisa apresentado à banca examinadora do Programa de Pós-graduação da Universidade Federal do Rio de Janeiro, por ocasião do meu ingresso como estudante de mestrado. Portanto, o ponto de partida para essa pesquisa foi à realização de leituras críticas das obras citadas ao longo da problematização, e outras referentes a temas como política pública, cidadania, democracia, questão étnico-racial etc. Desta forma, se tornou possível analisar o tema proposto a partir das categorias crítico-dialético presentes na teoria social marxista, o que abrange tanto a obra marxiana quanto sua posterior interpretação presente no marxismo ocidental. Portanto, a reflexão aqui exposta não está fechada, mas flexível às contradições da realidade a ser estudada, consistindo assim, num processo dialético em que o instrumento que determina a intervenção é determinado pela realidade a que se propõe intervir.

\section{BREVE HISTÓRICO DAS RELAÇÕES RACIAIS NO BRASIL}

Ao analisarmos o processo histórico de constituição da sociedade brasileira, a conclusão a que chegamos, é que não há nada do qual podemos nos orgulhar, pois, o que temos de herança, [...] é o resultado da história de um país retardatário, recheada de atrocidades cruéis contra as camadas populares, a começar contra os índios e negros na colonização, e se perpetuando contra os seus descendentes e os imigrantes pobres [...] (MENEGAT, 2008. p. 6).

Os projetos de colonização obtiveram o impulso necessário para sua legitimação e o discurso racista da desumanização do negro seguia seu curso, propagando o pensamento da inferioridade entre as raças ${ }^{4}$. Ainda hoje percebemos que a sociedade brasileira tem o racismo e suas práticas hierarquizantes como base das relações sociais entre negros e não negros. Neste sentido, uma das principais doutri-

4 Optamos por utilizar o conceito de raça por concordar que “(...) 'raça' não é apenas uma categoria política necessária para organizar a resistência ao racismo no Brasil, mas é também categoria analítica indispensável: a única que revela que as discriminações e desigualdades que a noção brasileira de 'cor' são efetivamente raciais e não apenas de classe" (GUIMARÃES, 2002, p. 51). 
nas racistas do século passado, foi o darwinismo social5, que se encarregou de explicar, pelas leis biológicas, a determinação da civilização e o progresso humano como sendo resultado da competição entre raças, vencendo apenas os mais aptos, neste caso, os da raça branca.

Gilberto Freyre desenvolveu um importante trabalho em 1930, intitulado Casa Grande e Senzala, este ganhou repercussão não só aqui no Brasil, mas em vários outros países, tornando-se uma das mais relevantes obras brasileiras a discutir o tema da "democracia racial". Bento (2002), ressalta que Freyre fornece à elite branca os argumentos necessários para continuarem usufruindo dos privilégios raciais. A distância social entre dominantes e dominados é modificada pelo cruzamento inter-racial e segundo o autor, a diminuição desta distância abranda as contradições existentes e harmonizam as diferenças, isto traria como consequência uma diluição de conflitos. Porém, ao postular a conciliação entre as raças e suavizar o conflito, o autor nega a existência do preconceito e da discriminação, culpabilizando os "mestiços e negros" pelo insucesso.

Há na temática da miscigenação um aspecto contraditório, pois, ao mesmo tempo em que seria a salvação do país, porque os negros desapareceriam, também era vista como elemento que "estragaria o potencial de progresso dos brancos". No entanto, foi por meio da miscigenação se deu a construção do que é divulgado como "identidade brasileira". O resultado da miscigenação, para tal ideologia daria para o negro a esperança, o sonho, à ilusão de que os seus herdeiros, talvez, pudessem ser incluídos como parte da sociedade, mas, porque "carrega um duplo sentido negativo: o de denegação de identidade de grupo e o de denegação de uma humanidade comum". (ANDRÉ, 2008, p.120 e 121)

Os projetos racistas de miscigenação e do ideário de embranquecimento foi utilizado por muito tempo como ato político, e ideológico. Nos dias de hoje, este projeto ainda em curso, reforça a imagem de que o Brasil é um país mestiço e democrático. De fato, este país é um caldeirão étnico, porém nada democrático do ponto de vista eco-

5 Considera uma das principais doutrinas racistas do século XIX, radicalizou o primado das leis biológicas na determinação da civilização, afirmando que o progresso humano é um resultado da luta e da competição entre raças, vencendo os mais capazes ou os mais aptos, no caso os brancos, por que as demais raças, principalmente os negros, acabariam sucumbindo à seleção natural e social. (SEYFERTH, 1996, p. 41). 


\section{tempordlis}

nômico, social, de gênero, cultural e racial. Embora o projeto de embranquecimento físico tenha fracassado, outras formas de embranquecimento permanecem no imaginário da nossa sociedade, como o embranquecimento cultural, psicológico, social, econômico. A tentativa de branqueamento se estende até os anos 30 do século XX, em que, só a partir de então, foi substituído pelo discurso ideológico da democracia racial ${ }^{6}$.

Ao discorrer sobre o mito da democracia racial Fernandes (1972), coloca a complexidade da questão racial em debate. Para a população negra, as habilidades em lidar com estas questões, vão para além da aparência, visto que, os espaços de poder são extremamente racializados, as funções que dão "status", empregos e profissões consideradas de "mais valor", não são desempenhadas por negros, ao contrário, continuam estrangeiros dentro do seu próprio país. No entanto, para o autor, isso demonstra apenas, técnicas específicas de dominação social, que servem apenas para manter a ordem social que discrimina e coloca seres humanos com diferenças fenotípicas em posição de desigualdade. (FERNANDES, 1972, p. 26 e 27).

Estereotipar o negro de forma negativa impedia que o "homem branco" se notasse como principal agente de propagação do racismo, como também suscita uma barreira invisível universal que impedia qualquer definição rápida da imagem do negro e assim facilitasse a passagem do trabalho escravo para o trabalho livre e assim acelerasse a proletarização do "homem de cor". (p.141).

Alguns autores se destacam como intérpretes do momento histórico, que marca o início de uma nova fase sobre as pesquisas raciais no Brasil7. Estes analisam as desigualdades na estrutura social e no

6 "[...] a idéia de que existia uma democracia racial no Brasil vem sendo fomentada há muito tempo. No fundo, ela constitui uma distorção criada no mundo colonial, como contraparte da inclusão de 'mestiços' no núcleo legal das grandes famílias, ou seja, como reação a mecanismos efetivos de ascensão social do 'mulato'. O fundamento pecuniário da escravidão e certos efeitos severamente proscritos, mas, incontornáveis da miscigenação contribuíram para que se operasse uma espécie de mobilidade social vertical por infiltração, graças à qual a composição dos estratos raciais dominantes teve de adquirir certa elasticidade [...]". (FERNANDES, 1972. Apud ANDRÉ, 2008, p. 150).

7 Xavier (2006) destaca, dentre os principais autores desse novo período - que se inicia na década de 1970 e se estende até os dias atuais, com as propostas e a implementação de políticas afirmativas em favor da população negra no Brasil Hasenbalg e Telles. Esses autores têm dado uma importante contribuição à análise 
sistema de classes, dando ênfase à condição racial em meio a essas desigualdades, estudando a questão racial em face à estratificação social. Neste sentido, o autor rompe com as visões anteriores, nega a democracia racial descrita por Freyre e apresentam dados que comprovam que o desenvolvimento do capitalismo no país não resultou na integração do negro na sociedade de classes, como previsto por Fernandes (1978), conforme observamos na citação a baixo:

\begin{abstract}
A discriminação e preconceito raciais não são mantidos intactos após a abolição, pelo contrário, adquirem novos significados e funções dentro das novas estruturas e as práticas racistas do grupo dominante branco que perpetuam a subordinação dos negros não são meros arcaísmos do passado, mas estão funcionalmente relacionadas aos benefícios materiais e simbólicos que o grupo branco obtém da desqualificação competitiva dos não brancos. (HASENBALG, 1979. p.84).
\end{abstract}

Telles (2003) analisa alguns dados que confirmam a tese apresentada por Hasenbalg (1979) de que o desenvolvimento econômico capitalista, por si só não foi capaz de eliminar as desigualdades de cunho racial existentes no Brasil. $\mathrm{O}$ autor expõe e analisa a situação dessas populações, bem como as mais recentes políticas implantadas pelo governo brasileiro, de acesso dos negros ao mercado de trabatho e à universidade.

Essas políticas espelham-se nas medidas adotadas pelo governo dos Estados Unidos na década de 1960, denominadas políticas de ação afirmativa. Essas políticas atuam como alternativas de combate à discriminação, visando à garantia da equidade e inclusão social. Alguns autores como Brandão (2004), Jaccoud (2008) e Gomes (2001) afirmam que as políticas afirmativas são uma alternativa viável no sentido de promover justiça social e propiciar aos beneficiados, subsídios de se incluir socialmente, bem como demonstrar o quão intenso é o racismo no país.

Silva (2009) analisa que a Constituição Federal de 1988 pode ser considerada um grande avanço nesse aspecto, pois reconhece o racismo e o preconceito racial como fenômenos presentes na sociedade brasileira, sustentando a necessidade de combatê-los. Entretanto, destaca que a inclusão do tema racial na agenda das políticas públicas responde principalmente a um esforço inovador do movimento social

das relações raciais, da discriminação e do racismo no Brasil. 


\section{tempordlis}

negro no sentido de estimular, no debate político, a necessidade não apenas de combater o racismo, mas de efetivamente atuar na promoção da igualdade racial. Nesse contexto, inicia-se a implantação de ações afirmativas no Brasil.

As ações afirmativas se definem como políticas públicas (e privadas) voltadas à concretização do principio constitucional da igualdade material e à neutralização dos efeitos da discriminação racial, de gênero, de idade, de origem nacional e de compleição física. Na sua compreensão, a igualdade deixa de ser simplesmente um princípio jurídico a ser respeitado por todos, e passa a ser um objetivo constitucional a ser alcançado pelo Estado e pela sociedade (GOMES, 2001, p. 21).

Em 2001, foi realizada a III Conferência Mundial contra o Racismo, a Discriminação Racial, a Xenofobia e as Formas Conexas de Intolerância, em Durban, na África do Sul, conhecida como a "Conferência de Durban" " . Esta conferência resultou em um documento que reconhece a responsabilidade histórica do Estado brasileiro "pelo escravismo e pela marginalização econômica, social e política dos descendentes de africanos", torna-se um marco mundial na luta contra as discriminações raciais. (CAVALLEIRO, 2006, p. 18).

Após a Conferência de Durban, mediante as reivindicações do movimento negro, o Estado brasileiro passou a desenvolver projetos que objetivavam promover políticas e programas para a população afro-brasileira e valorizar a história e a cultura do povo negro, como a Lei $n^{\circ} 1.0639 / 03$, que versa sobre o ensino da História e Cultura Afro-brasileira e Africana, ressalta a importância da cultura negra na formação da sociedade brasileira. (CAVALLEIRO, 2006). Todavia, Silva et al. (2009) atentam que parte das iniciativas que visam à promoção da igualdade racial pode ser classificada como inicial, pontual ou de limitada cobertura. Muitas ações são marcadas por falta de continuidade, de recursos ou de abrangência.

Salientamos a necessidade de ampliação do debate acerca dessa temática, no sentido do reconhecimento e da relevância dessas

8 Alguns dos temas marcaram esse contexto histórico, porém, outros, foram considerados como urgentes e polêmicos e sacudiram a conferência supracitada, dentre eles: a discussão acerca das ações afirmativas, bem como das estratégias de enfrentamento ao racismo. Nessa conferência, participaram 173 países, 4 mil organizações não governamentais (ONGs) e um total de mais de 16 mil participantes (IBGE, 2008). 


\section{tempordilis}

intervenções, especialmente por parte da população brasileira, mas também propor ações efetivas de enfrentamento. É importante refletir a (re) formulação de novos valores e percepções por parte da sociedade ante a esse contexto, pois a ideia de "democracia racial" ainda vive no imaginário da população brasileira, o que dificulta a implantação dessas políticas denominadas ações afirmativas.

\section{RAÇA E IDENTIDADE}

O processo social pelo qual se envolve a formação e a conservação da identidade é condicionado por uma estrutura social. A construção da identidade depende da identificação de valores, de símbolos e outros referências, mas não só disto, essa construção depende ainda de uma interação entre indivíduos. Assim, se neste processo de interação houver formas preconceituosas e discriminatórias de uma raça, para com a outra, compreendemos que a identidade será fragmentada, ou mesmo negligenciada, fazendo com que os indivíduos inferiorizados busquem a "identidade ideal" uma vez que esta se apresenta como modelo de "identidade superior".

Cuche (1999), afirma que o conceito de identidade implica necessariamente a uma vinculação consciente do sujeito que se dá através da diferenciação entre "eu" e os outros. Portanto, pode-se afirmar que a identidade atua ao mesmo tempo num duplo processo, pois permite que o indivíduo ou grupo se localize e seja localizado em um determinado sistema social.

Segundo a reflexão do autor, a identidade surge do processo de vinculação consciente do sujeito, no caso da população pertencente ao grupo étnico de descendência africana, que ocorre um intenso movimento de imitação do outro e há, no interior desses grupos, uma maioria que não só negligencia a sua origem, como também se coloca como pertencente a qualquer outro grupo, que não seja o de ascendência africana.

Nesta direção, recorremos a Fanon (2008) na tentativa de entender como a identidade racial se constrói pela via da alienação, num processo dialético entre a negação e a afirmação, pois, para o autor, o "... racismo dos negros contra o negro é um exemplo da forma de narcisismo no qual os negros buscam a ilusão dos espelhos que oferecem um reflexo branco." (p. 15) e, ainda, como ocorre neste processo os muitos níveis de narcisismo, impedindo que o outro se reconheça 


\section{temporalis}

neste mesmo reflexo.

O autor afirma ainda que, romper com a alienação entre o homem negro é algo intensamente trabalhoso e, não de outra forma, mas somente com o rompimento do elo existente entre "colonização" e "alienação" e a destruição dos instrumentos que os alimentam, será possível a superação da condição alienante que mantém os homens atados a poderosas correntes, como é possível observar na reflexão que se segue.

Mas, eu, homem de cor, na medida em que me é possível existir absolutamente, não tenho o direito de me enquadrar em um mundo de reparações retroativas. Eu, homem de cor, só quero uma coisa: que jamais o instrumento domine o homem. Que cesse para sempre a servidão do homem pelo homem. Ou seja, de mim por outro. Que me seja permitido descobrir e querer bem ao homem, onde quer que ele me encontre. (FANON, 2008, p.p 190 e 191).

É possível o desenvolvimento de ações que superem as contradições impostas, num nítido processo que subordina o homem negro e lhe retira a capacidade de criar condições para uma sociedade que não hierarquize as relações entre os homens, mas que os unam num propósito de assegurar a possibilidade de uma vida plena. Nosso anseio é que este contramovimento também atue na desconstrução das falas e posições fincadas na ideia de que existem raças, culturas e sociedades superiores a outras, pois, acreditamos que tais posições contribuem para o acirramento das desigualdades sociais e raciais existentes.

Compreender a constituição das identidades de classes e sua mobilidade como um "movimento de contradições", onde, através de um processo de negação, tais contradições se elevam, conforme aponta Bogo, (2010). Ou seja, quando a classe trabalhadora, ao negar a burguesia, através do conflito e não da conciliação, assume o lugar de dominante, trazendo consigo novas determinações, onde o Estado também se apresenta como instrumento, colocando acima dele a "ditadura do proletariado", alterando assim a ordem democrática da maioria contra a minoria.

A existência da classe é que direciona as identidades e neste processo, uma classe se torna condição necessária para a existência da outra. E nesta "guerra de posições" para que haja emancipação de dominados por dominantes, a organização da classe se faz absoluta- 
mente necessária. Esta não é uma luta fácil, pois nela ocorrem duras batalhas que vão desde a ruptura entre as classes, como também a elevação do nível de conscientização e solidariedade entre os seus componentes, entretanto, é sabido que o capitalismo não existe sem classes e ao entrar nesta disputa, e se vencer, a classe trabalhadora se constituirá como classe dominante. (BOGO, 2010. p. 9 e 10).

O capitalismo avança e se constitui cada vez mais voraz obstinado em sua necessidade de produção de lucro e acumulação. Crises financeiras, políticas, sociais, culturais, e outras. atingem todo o globo, provocando sérias e profundas mudanças, sobretudo, ideológicas. $\mathrm{O}$ aumento das forças neoconservadoras têm crescido de forma exponencial, aliadas a um processo intenso de discriminação e violência, atingindo as várias esferas da sociedade.

Almeida (2013) afirma que neste processo ocorre a naturalização da violência e naturalizá-las significa transformá-las em desigualdades.

[...] A naturalização do que é histórico ganha legitimidade pelo poder hegemônico e oculta a violência, as hierarquias (de poder nas relações sociais) produzidas por estereótipos cuja função é biologizar o que é social nas relações e práticas sociais. A naturalização é a mediação para a essencialização da vida social. É, por assim dizer, a perpetuação da hegemonia do capital sob a experiência de vida dos sujeitos sociais concretos: negros (as), índios (as), população LGBT (lésbicas, gays bissexuais e travestis), crianças, idosos, pessoas com deficiência e o legado religioso não hegemônico [...]. (ALMEIDA, 2013, p.138).

De acordo com a reflexão da autora, entendemos que para romper com a sociabilidade burguesa à qual fomos condicionados, é preciso antes de tudo desconstruíla. O desafio, portanto, consiste em ultrapassar tal estrutura, objetivando uma transformação radical que nos permita caminhar na construção de outra forma de vida, que afirme os valores emancipatórios, e nos possibilite viver em plenitude e liberdade.

Os indivíduos observam suas ações, resumidas segundo suas atuações, em aspectos diversos, como políticos, culturais, econômicos, social, entre outros. aquilo que os motivem, bem como os façam compreender tal movimento, ou seja, os processos históricos a partir das mudanças estruturais da sociedade. Da observação, surge a necessidade de compreender os múltiplos elementos, que perpassam a 


\title{
tompordlis
}

constituição da classe social. Deste modo, podemos afirmar que tanto as ações, quanto a maneira de viver dos indivíduos, são de alguma maneira, determinados pelas relações estabelecidas com os meios de produção, com os bens materiais e culturais e com as relações de poder presentes na sociedade.

Portanto, é necessário, compreender o que está para além da conjuntura classista, ou dito de outra forma, é preciso que ao analisar a questão de classe, sejam também ultrapassadas as fronteiras econômicas das classes sociais. Para Marx (1995), a política, as ideologias e inclusive a cultura, junto com as determinações econômicas, atuam no processo de constituição da classe social.

\begin{abstract}
[...] a escala e a radicalidade da questão racial no Brasil podem ser consideradas condições fundamentais não só da luta pela eliminação do preconceito racial, mas também da transformação da sociedade brasileira como um todo e, fundamentalmente, da verdadeira construção de uma sociedade nacional, articulada, viva, em movimento, que a sociedade civil e o Estado desenvolvam-se de forma articulada e fluente e que a "população" se transfigure em "povo", no sentido de que o povo se constitui quando se compõe de "cidadãos", de pessoas situadas e integradas, participantes e ativas, em todas as esferas da sociedade, públicas e privadas [...] (IANNI, 2005, p. 11)
\end{abstract}

A ignorância sobre as reais condições de vida da população negra acaba por contribuir com a manutenção das desigualdades e discriminações raciais. Assim, a partir do momento que os indivíduos se reconhecem, aceitam e reivindicam sua origem, seja ela qual for. Ocorre assim uma mudança de comportamento, pois passam a não mais aceitar as desigualdades assimétricas decorrentes da sua condição de pertencimento ao grupo étnico-racial.

Silva e Hasenbalg (1992), afirmam que o vínculo entre raça e classe se dá quando a raça funciona como mecanismo de seleção social, determinando o lugar onde cada sujeito deve ocupar. Assim, a condição étnico-racial funciona dentro da lógica capitalista inclusive como um critério de seleção para a projeção social. Portanto, nessa lógica, o sistema capitalista se sustenta a partir da relação de exploração de classe e, por sua vez, essa exploração se expressa através de múltiplas formas de dominação, dentre elas as de gênero, raça e etnia, pois, por detrás dos preconceitos, sempre se encontram fatores econômicos, nos quais se escoram aqueles que querem explorar 
a força de trabalho a quem imputaram algum tipo de inferioridade.

\section{QUESTÃO RACIAL E SERVIÇO SOCIAL}

O caráter prático-interventivo da profissão busca a efetivação dos direitos de cidadania ${ }^{9}$ dos usuários. Por ser o Serviço Social uma profissão de caráter prático-interventivo, que efetiva sua prática na operacionalização do nexo entre as instituições sociais e os serviços que estas devem prestar, além de atender aos usuários com necessidades e demandas na busca pelo acesso aos direitos e serviços, entendemos que a "questão racial" se relaciona com as várias formas de produção e reprodução do capital, das relações sociais, das condições de vida, de cultura e de riqueza.

A análise crítica das “expressões da questão social”, bem como sua origem e desenvolvimento histórico, além das demonstrações que as particularizam na sociedade capitalista, vem ganhando cada vez mais relevância na contemporaneidade. Conhecer suas fundamentações e as várias formas de manifestações constitui um grande desafio para o Serviço Social, pois, é a partir daí que são elaboradas respostas para o seu enfrentamento.

No tocante a esta profissão, chamamos a atenção para algumas de suas características, como por exemplo, ter na questão social a base de sua fundação enquanto especialização do trabalho. Sobre isto, Netto (2005) afirma que através da instauração da ordem monopólica, e, portanto, ocupando uma posição subordinada na divisão sociotécnica do trabalho o Serviço Social se profissionaliza, tornandose apenas executor das políticas públicas e mediador da contradição capital x trabalho, pois, são nessas bases que o Estado Burguês se enfrenta com a "questão social" ${ }^{10}$.

Das contradições e características que marcam o Serviço Social

9 Coutinho (1997), afirma que cidadania é entendida como a capacidade conquistada por alguns indivíduos, ou por todos de usufruírem dos bens socialmente produzidos, ou seja, é um processo de busca pela apropriação dos bens sociais pelo conjunto dos cidadãos.

10 Para o entendimento sobre o significado de "questão social", buscamos sua definição em Cerqueira Filho (1982), onde nos aponta que: a questão social engloba o "conjunto de problemas políticos, sociais e econômicos que o surgimento da classe operária impôs ao mundo, no curso da constituição da sociedade capitalista". Assim, a "questão social está fundamentalmente vinculada ao conflito entre o capital e o trabalho". 


\section{tompordlis}

brasileiro, destacamos que a temática étnico-racial também aparece como característica que marca esta profissão. Silva Filho (2004) aponta que apesar de relativamente nova, é possível destacar o aumento significativo da quantidade de estudantes negros a procurar pelo curso de Serviço Social. O autor ressalta que há tempos atrás este grupo étnico encontrava-se apenas no lugar de usuário dos serviços prestados. Entretanto, observamos que este dado ainda é pouco discutido por essa categoria profissional.

Rocha (2009), afirma que, analisar a inserção da temática étnico-racial no processo de formação profissional de serviço social, bem como sua relevância para a consolidação do Projeto Ético-Político da profissão, configura-se como um grande desafio, tendo em vista que existem alguns entraves que acabam por dificultar a realização de debates ressaltando a importância dessa realidade. Entre outros motivos, alguns entraves se dão pela baixa produção teórica acerca desses temas, e também pela pouca apropriação da categoria pela discussão das temáticas de cor/raça/etnia. A discussão étnico-racial sempre foi secundarizada por essa categoria profissional, e por muitos profissionais não é percebida como importante variável para uma análise crítica das relações sociais sob a perspectiva de totalidade.

Quanto à baixa produção de conhecimento no que tange à temática étnico-racial, Ferreira (2010) aponta que, até junho de 2010, a revista Serviço Social e Sociedade (uma das revistas mais importante em publicações teóricas acerca do Serviço Social brasileiro), desde o seu início, em 1939, já havia publicado cento e dois números e somente em três deles foram publicados artigos referente à temática étnico-racial.

As publicações estão nas revistas de número 79, com artigo de Matilde Ribeiro denominado de "As abordagens étnico-raciais no Serviço Social" publicado em 2004, e que discorria sobre a militância de assistentes sociais nos "movimentos negros" da década de 1980; ainda o número 81 "A questão racial na Assistência Social: um debate emergente" de Sarita Amaro do ano de 2005, abordando políticas de ação afirmativa; e por fim a de número 99 "A questão étnico-racial no processo de formação em Serviço Social”, de Roseli da Fonseca Rocha, publicado em 2009. (p. 11)

As novas exigências colocadas ao Serviço Social brasileiro contemporâneo se apresentam como "preocupações emergentes no âm- 
bito do serviço social, exigindo novas respostas profissionais", (IAMAMOTO, 2009). Nota-se ainda uma nova feição acadêmica profissional e social voltada à defesa do trabalho e dos trabalhadores, do compromisso com a afirmação da democracia, da liberdade, da igualdade e da justiça social no terreno da história, onde não cabe mais negligenciar a determinadas discussões. (p.4)

No entanto, é sabido que na sociedade brasileira há poucos espaços que se colocam como arena de debates acerca da temática étnico-racial. Isto não é um problema que se manifesta só entre a categoria profissional dos assistentes sociais. Porém, está preconizado no Código de Ética Profissional (1993), o compromisso na busca pela equidade e justiça social, pois, sem igualdade não há justiça. Portanto, em face desse posicionamento, torna-se necessário que tal categoria se aproprie de discussões que a façam exercer o seu compromisso ético e político.

Esta categoria profissional se coloca na luta pela afirmação de direitos dos usuários dos seus serviços, e se a questão racial também compõe o conjunto das relações sociais brasileiras, é urgente que tal debate ocupe o devido destaque na agenda e nos fóruns de formação profissional. É necessário também, que esta categoria assuma o compromisso político de debater outros assuntos que se interseccionam com a temática étnico-racial como classe, gênero, sexualidade e outros. Tendo em vista que,

\begin{abstract}
[...] silenciar, invibilizar o negro não é um ato restrito à história do Serviço Social, uma vez que "no registro que o Brasil tem de si mesmo o negro tende à condição de invisibilidade" (HASENBALG, 1982, p. 105). Cumpre desvendar os motivos pelos quais essa invisibilidade registra-se [...]. Afinal, "é preciso pensar nas especificidades dessa história brasileira, que fez da desigualdade uma etiqueta e da discriminação um espaço não formalizado" (SCHWARCZ, 2001, p. 36). Esta análise tem em mira que o silêncio sobre os negros na produção incipiente do Serviço Social não é um acidente mnemônico, mas um silêncio - e "silêncio não é sinônimo de ausência” (SCHWARCZ, 2001, p. 52). (FERREIRA, 2010. p. 13).
\end{abstract}

Portanto, escamotear tais discussões é também assumir uma posição política. E nisto, o Serviço Social brasileiro se diferencia das 


\section{temporalis}

demais profissões, uma vez que em seu Projeto Ético-Político, o lado que se optou em seguir, é o da classe trabalhadora, composta pela parcela mais empobrecida da sociedade brasileira, negros(as), mulheres, homossexuais, lésbicas, transexuais. Portanto, trata-se então, de que esta categoria atente-se para que a condição da população negra não seja subjugada ou secundarizada por quem se coloca como construtor de uma nova ordem societária, onde não cabem explorações e nem dominações seja elas de qual origem for.

Ao eleger os temas que urgem no debate sobre o "serviço social na cena contemporânea" (lamamoto, 2009), esta categoria busca não só responder às reais demandas do fazer profissional, como também responder as lacunas existentes entre a categoria e os usuários. Estes são, portanto, elementos fundamentais que contribuem para o processo de acumulação de forças que seguem em direção à outra forma de vida e de desenvolvimento social, inclusiva a todos os indivíduos.

Neste sentido (ROCHA apud IAMAMOTO 2008. p. 469) aponta a necessidade de se analisar as classes na história brasileira, pois, tal sociedade é marcada por importantes determinações étnico-raciais, regionais e culturais, rurais e urbanas, pois, é a partir do conhecimento desses elementos que se constroem estratégias reais e eficazes na luta contra a exploração dos indivíduos.

É, pois, nessas estruturas que se definem o lugar dos indivíduos. São relações sociais pautadas pelas relações de produção e pela estrutura classista e racista que rege esta sociedade. A luta pela sobrevivência se dá através de estruturas de poder e de organização em prol da manutenção dos privilégios. Nisto, residem as "determinações básicas das relações de integração e antagonismo raciais" (IANNI, 1978, p. 124).

Todavia, embora com a apresentação de pesquisas quantitativas e qualitativas ${ }^{11}$, estudos sérios e comprometidos com a busca pelo entendimento de como se estrutura a discussão racial na sociedade brasileira, surgem dúvidas. Qual seria a intenção, por detrás do silêncio, em se discutir a temática étnico-racial por essa categoria? Por que durante a sua atuação, o profissional de Serviço Social tem dificuldades em perguntar a cor/raça ou a pertença étnica da população atendida? Ou ainda, por que o próprio profissional de serviço social

11 Cf. Paixão (2009-2010) e Ipea e Dieese (2008). 
tem dificuldades em se autodeclarar? São questões como essas que expressam a relevância deste estudo.

A ausência do debate, bem como a falta de conhecimento sobre os dados apontados acima nos instrumentos de informação do assistente social resulta em uma invisibilidade racial, e a esta prática, interpretamos como uma posição política de negação. Afirmamos, pois, que seja numa sociedade de exploração capitalista ou em qualquer outra ordem social, se o racismo não for alvo de enfrentamento e combate, certamente as desigualdades raciais marcarão as relações sociais. Neste sentido, estamos de acordo que:

O discurso competente é crítico quando vai à raiz e desvenda a trama submersa dos conhecimentos que explica as estratégias de ação. Essa crítica não é apenas mera recusa ou mera denúncia do instituído, do dado. Supõe um diálogo íntimo com as fontes inspiradoras do conhecimento e com os pontos de vista das classes por meio dos quais são construídos os discursos: suas bases históricas, a maneira de pensar e interpretar a vida social das classes (ou segmentos de classe) que apresentam esse discurso como dotado de universalidade, identificando novas lacunas e omissões. (IAMAMOTO, 2009. p. 2).

Em razão da reflexão traçada até aqui, buscamos um diálogo crítico acerca de temas que para nós são urgentes e caros. Se compreendermos que é pela história da sociedade e das relações sociais que se constroem ações propositivas e objetivas com vistas a enfrentar a herança racista, patriarcal e do pensamento eurocêntrico, e, portanto, colonizador, e assim, nos perguntamos por que não fazê-lo também no interior desta profissão?

Questionar a quem interessa o silêncio sobre a temática étnico-racial nessa categoria profissional não se configura como tarefa fácil, é necessário pautá-la para que esses e outros temas não sejam secundarizados e/ou omitidos. Há que se criar espaços críticos em que sejam produzidos conhecimentos reais sobre a história das relações raciais, e dos impactos dessa manifestação para a vida dos usuários negros (as) e também do profissional que assim se reconheça, pois, compreendemos que

[...] um profissional culturalmente versado e politicamente atento ao tempo histórico; atento para decifrar o não-dito, os dilemas implícitos no ordenamento epidérmico do discurso autorizado pelo poder [...] capazes de 


\section{temporolis}

elaborar estratégias de ação estabelecidos a partir da elucidação das tendências presentes no movimento da própria realidade, decifrando suas manifestações particulares no campo sobre o qual incide a ação profissional. (IAMAMOTO, 2009. p. 3).

Não estamos aqui buscando uma ação utópica ou messiânica. Porém, almejamos sim uma atuação profissional que entenda os indivíduos como sujeitos históricos e compreendida em suas especificidades e seus múltiplos determinantes. Que a atuação profissional seja inspirada em uma visão capaz de desnaturalizar o que se apresenta como real e caminhe na perspectiva revolucionária de uma ação totalizante e não fragmentada. Sem fatalismos ou ações individuais, particularizadas e focalizadas, mas com possibilidades concretas de enfrentamento às desigualdades e assimetrias impostas pela ordem capitalista.

\section{CONSIDERAÇÕES FINAIS}

Levamos em consideração alguns elementos que oferecem base e justificam a importância do presente tema para o Serviço Social, tendo em vista o caráter prático-interventivo da profissão que busca a efetivação dos direitos de cidadania dos usuários. Este artigo, portanto, apontam alguns limites, mas também muitos avanços obtidos pela categoria quanto à consolidação e concretização de projetos que vão ao encontro do enfrentamento das desigualdades aqui apontadas.

Compreendemos que existe todo um esforço e compromisso das nossas entidades representativas para realizar o que Netto (1996) nos propõe, ao dizer que: ao profissional de Serviço Social cabe converter as possibilidades em realidade, de forma que estas possam atuar na contra-hegemonia daquilo que está posto, bem como elaborar e desenvolver respostas e ações qualificadas que atendam as demandas trazidas pelos usuários, quer sejam explícitas ou implícitas.

Neste sentido, o novo Código de Ética do assistente social de 1993, a nova Lei de Regulamentação Profissional (Lei de n 8.662/93) e as Diretrizes Curriculares para a Formação Profissional de Serviço Social da ABEPSS (1996), formam um conjunto importantíssimo de ferramentas que buscam fortalecer nosso Projeto Ético-Político. Nessas ferramentas, encontramos preconizados a importância de reflexões e o desenvolvimento de estratégias que busquem maior compreensão desta temática para que, assim, o enfrentamento do racismo e das 
assimetrias sociais existentes seja possível. É dever dos assistentes sociais, buscar, para além de ferramentas técnico-operativas, instrumentos que materializem nosso compromisso ético e político na busca por uma sociedade justa e igualitária que respeite as diferenças, sem colocá-las na condição de desiguais (ROCHA, 2009. p. 557).

Portanto, afirmamos a fundamental necessidade, de superação das assimetrias que subordina os homens e mulheres negros, bem como das intersecções que se relacionam com essas variáveis. Só há possibilidade de se construir uma ação social eficaz se, de fato, houver a efetivação de um processo revolucionário diante da hegemonia do capital na totalidade da produção social, desenvolvida ao lado da economia, no campo da política, da cultura e da educação e ainda da dimensão simbólica, com atribuições distintas, mas com significados relacionados ao modo de vida dos indivíduos, não só no âmbito da questão étnico-racial como também na estrutura da própria classe, e sendo direcionadas como questões igualmente importantes.

É preciso ir muito além dos discursos e mover o recalque que mascara a sociedade dos privilégios, mas que na verdade, mantém tudo exatamente no mesmo lugar que sempre esteve e assim, superar ideologias como o mito da democracia racial no Brasil e toda a manipulação engendrada para a sua manutenção e efetivação.

Descolonizar o conhecimento é tarefa difícil, porém, essencial também, deve ser ir para além das aparências e olhar com lente de aumento para a intrínseca relação que existe entre o racismo e a estrutura de classes. Neste sentido, compreendemos que as classes sociais dependem da concepção ideológica de cada indivíduo e o que os unifica é o desejo de uma vida plena. Portanto, as possibilidades de superação da desigualdade social só pode se tornar realidade se a transformação social caminhar em conjunto com o respeito das particularidades históricas desta e de outras sociedades.

Concluímos que, seja numa sociedade de exploração capitalista ou em qualquer outra ordem social, se o racismo não for alvo de enfrentamento e combate, certamente as desigualdades raciais sempre marcarão as relações sociais. Portanto, a construção de uma sociedade livre, deve ser pensada com base em uma perspectiva de totalidade, onde a realidade social é constituída por múltiplos determinantes como: classe, raça, etnia, gênero entre outros. 


\section{temporalis}

\section{REFERÊNCIAS}

ABEPSS. Associação Brasileira de Ensino e Pesquisa em Serviço Social. Diretrizes gerais para o curso de Serviço Social. Rio de Janeiro: ABEPSS, 1996.

ANDRÉ, Maria da Consolação. O ser negro: a construção de subjetividades em afro-brasileiros. Brasília, DF: LGE Editora, 2008.

ALMEIDA, Magali, S. Exercício do Serviço Social sem ser discriminado, nem discriminar, por de inserção de classe social, gênero, etnia, religião, nacionalidade, opção sexual, idade e condição física. In: CRESS. Conselho Regional de Serviço Social (Org.). Projeto ético-politico e exercício profissional em Serviço Social: os princípios do código de ética articulados á atuação crítica de assistentes sociais. Rio de Janeiro: CRESS, 2013.

BENTO, Maria Aparecida Silva Branqueamento e branquitude no Brasil. In: ; CARONE, Iray (Orgs.). Psicologia social do racismo: estudos sobre branquitude e branqueamento no Brasil. Petrópolis, RJ: Vozes, 2002.

BOGO, Ademar. Identidade e luta de classes. 2. ed. São Paulo: Expressão Popular. 2010.

BRANDÃO, André Augusto. Miséria da periferia: desigualdades raciais e pobreza na metrópole do Rio de Janeiro. Rio de Janeiro: Pallas, 2004.

BRASIL. Lei n. 8.662, 7 de junho de 1993. Dispõe sobre a profissão do Assistente Social. Diário Oficial da União, Brasília-DF, 8 jul. 1993. Disponível em: < http://www.planalto.gov.br/ccivil_03/leis/L8662.htm> Acesso em: 30 jun. 2013.

CAVALLEIRO, Eliane. Valores civilizatórios: dimensões históricas para uma educação anti-racista. In: BRASIL. Ministério da Educação. Orientações e ações para a educação das relações étnicorraciais. Brasília, DF: SECAD, 2006.

CERQUEIRA FILHO, Gisálio. A “questão social” no Brasil: crítica do discurso político. São Paulo: Civilização Brasileira, 1982.

COUTINHO, Carlos Nelson. Notas sobre cidadania e modernidade. Praia Vermelha, Rio de Janeiro, v.1, n.1, p. 145-165, 1997. 
CUCHE, Denys. A noção de cultura nas ciências sociais. São Paulo: EDUSC, 1999.

FANON, Frantz. Pele negra, máscaras brancas. Tradução de Renato da Silveira. Salvador: EDUFBA, 2008.

FERREIRA, Camila Manduca. O negro na gênese do Serviço Social (Brasil, 1936-1947). 2010. 203 f. Dissertação (Mestrado em Serviço Social)- Universidade Federal do Rio de Janeiro, Rio de Janeiro, 2010.

FERNANDES, Florestan. O negro no mundo dos brancos. São Paulo: Difel, 1972.

. A integração do negro na sociedade de classes. 3. ed. São Paulo: Ática, 1978.

FREYRE, Gilberto. Casa grande e senzala: introdução à história da sociedade patriarcal no Brasil. Rio de Janeiro: Record, 2002.

GUIMARÃES, Antônio Sérgio. Classes, raças e democracia. São Paulo: Editora 34, 2002.

GOMES, Joaquim Barbosa. Ação afirmativa e princípio constitucional de igualdade. Rio de Janeiro: Renovar, 2001.

GOMES, Joceline. Conferência de Durban completa 10 anos. Fundação Cultural Palmares, 2011. Disponível em: < http://www.palmares.gov. $\mathrm{br} / \mathrm{p}=13958>$ Acesso em: 10 nov. 2012.

HASENBALG, Carlos. Discriminação e desigualdades raciais no Brasil. Belo Horizonte, EdUFMG; Rio de Janeiro: Iuperj, 2005.

HASENBAL, Carlos. Desigualdades raciais no Brasil. Rio de Janeiro: Graal, 1979.

IAMAMOTO, M. V. O Serviço social na contemporaneidade: trabalho e formação profissional. 14. ed. São Paulo: Cortez, 2008.

. O Serviço Social na cena contemporânea. In. CFESS. ConseIho Federal de Serviço Social. Serviço Social: direitos sociais e competências profissionais. Brasília, DF: CFESS/ ABEPSS, 2009.

IANNI, Octávio. As metamorfoses do escravo: apogeu e crise da escravatura no Brasil meridional. São Paulo: Hucitec, 1988. 


\section{temporolis}

; SILVA, Benedita da; SANTOS, Cevanilda Gomes et al. O negro e o socialismo. São Paulo: Editora: Fundação Perseu Abramo, 2005. (Coleção Socialismo em Discussão).

JACCOUD, Luciana. 0 combate ao racismo e à desigualdade: o desafio das políticas públicas de promoção da igualdade racial. In: THEODORO, Mário. (Org.). As políticas públicas e a desigualdade racial no Brasil 120 anos após a abolição. Brasília, DF: IPEA, 2008.

. SILVA, Adaiton; ROSA, Waldemir et al. Entre o racismo e a desigualdade: da constituição a promoção de uma política de igualdade racial (1988-2008). In: JACCOUD, Luciana (Org.). A construção de uma política de promoção da igualdade racial: uma análise dos últimos 20 anos. Brasília, DF: IPEA, 2009.

. Racismo e República: o debate sobre o branqueamento e a discriminação racial no Brasil. Brasília, DF: IPEA, 2008.

MARX, K. O capital: crítica da economia política. São Paulo: Nova Cultural, 1995. Livro 1. v.1.

. Manuscritos econômico-filosóficos: e outros textos escoIhidos. Tradução de José Carlos Bruni et al. São Paulo: Abril Cultural, 1985.

. Contribución a la crítica de la filosofía del derecho de Hegel. In: _ ; RUGE, Arnold. Los Anales Franco-Alemanes. Barcelona: Ediciones Martinez Roca, 1970.

MENEGAT, Marildo. Sem lenço nem aceno de adeus: formação de massas em tempos de barbárie: como a esquerda social pode enfrentar essa questão? Praia Vermelha, Rio de Janeiro, n. 18, p. 146-177, 2008.

PAULO NETTO, José. Capitalismo monopolista e Serviço Social. São Paulo: Cortez, 2005.

- Transformações societárias e Serviço Social: Notas para uma análise prospectiva da profissão no Brasil. Serviço Social \& Sociedade, São Paulo, n. 50, p. 87-132, 1997.

PAIXÃO, Marcelo. A dialética do bom aluno: relações raciais e sistema educacional brasileiro. Rio de Janeiro: Editora FGV, 2008.

; ROSSETTO, Irene; MONTOVANELE, Fabiana et al. Relatório anual das desigualdades raciais no Brasil 2009-2010: Constituição ci- 
dadã e seguridade social e seus efeitos sobre a assimetria da cor ou raça. Rio de Janeiro: Garamond Universitária/LAESER, do Instituto de Economia da UFRJ, 2010.

; CARVALHO, Luiz M. (Orgs). Relatório anual das desigualdades raciais no Brasil 2007-2008. Rio de Janeiro: Garamond Universitária/LAESER, do Instituto de Economia da UFRJ, 2008.

PINTO, Elisabete Aparecida. O Serviço Social e a questão étnico-racial. São Paulo: Terceira Margem, 2003.

ROCHA, Roseli da Fonseca. A questão étnico-racial no processo de formação em Serviço Social. Serviço social \& Sociedade, São Paulo, n. 99, p. 540-561, jul./set. 2009.

SANSONE, Lívio. As relações raciais em Casa Grande \& Senzala revisitadas á luz do processo de internacionalização e globalização. Rio de Janeiro. Fiocruz/CCBB, 1996.

SEYFERTH, Giralda. Construindo a nação: hierarquias raciais e o papel do racismo na política de imigração e colonização. Rio de Janeiro. Fiocruz/CCBB, 1996.

SCHWARCZ, Lilia Moritz. Gilberto Freyre: adaptação, mestiçagem, trópicos e privacidade em novo mundo nos trópicos. In: LUND, Joshua; McNEE, Malcolm (Ed.). Gilberto Freyre e os estudos latinoamericanos. Pittsburgh: Instituto Internacional de Literatura Iberoamericana, Universidade de Pittsburgh, 2006.

SILVA FILHO, José B. da. A questão do negro no curso de graduação em Serviço social da Universidade Federal Fluminense. 2004. $126 \mathrm{f}$. Dissertação (Mestrado em Política Social)- Universidade Federal Fluminense, Rio de Janeiro, 2004.

SILVA, Nelson do V. HASENBALG, Carlos A. Relações raciais no Brasil contemporâneo. Rio de Janeiro: Rio Fundo, IUPERJ, 1992.

TELLES, Edward. Racismo à brasileira: uma nova perspectiva sociológica. Rio de Janeiro: Dumará, 2003.

XAVIER, Solange Procópio. Relações raciais e políticas de ação afirmativa para a população negra no Brasil. 2006. 118 f. Dissertação (Mestrado em Desenvolvimento Social) - Universidade Estadual de Montes Claros, Montes Claros, 2006. 
